\title{
Online Teaching and Learning of Higher Education in India during COVID-19 Emergency Lockdown
}

\author{
Girisha Lakshman Naik ${ }^{1 \star}$, Malteshkumar Deshpande ${ }^{1}$, D C Shivananda ${ }^{1}$, C P Ajey ${ }^{1}$, G C Manjunath Patel ${ }^{1}$
}

\author{
${ }^{1}$ PES Institute of Technology and Management, Shivamogga, Affiliated to Visvesvaraya Technological University, Belagavi, INDIA \\ *Corresponding Author: girinaik@gmail.com
}

Citation: Naik, G. L., Deshpande, M., Shivananda, D. C., Ajey, C. P., \& Manjunath Patel, G. C. (2021). Online Teaching and Learning of Higher Education in India during COVID-19 Emergency Lockdown. Pedagogical Research, 6(1), em0090. https://doi.org/10.29333/pr/9665

\begin{tabular}{|c|c|}
\hline ARTICLE INFO & ABSTRACT \\
\hline Received: 25 Jun. 2020 & The COVID-19 pandemic has generated a world-wide consciousness that the present way of lifestyle does not \\
\hline Accepted: 3 Dec. 2020 & $\begin{array}{l}\text { work. There are many areas need the revolutionary changes and it has become obvious, one among is educational } \\
\text { sector. In India, educational institutes/universities remain closed since the mid of March-2020, because of the fast } \\
\text { spread of COVID-19. Emergency lockdown has a preventive measure upended the life of students, parents and } \\
\text { teachers. To combat this inevitable crisis educational sectors started conducting the online classes. The sudden } \\
\text { changeover in teaching/learning method has raised new challenges and opportunities. In this study, a survey } \\
\text { based-investigation has been carried out to analyse the efficacy of online teaching and learning method compared } \\
\text { to traditional teaching method. A questionnaire-based survey is prepared to collect the data from different degree } \\
\text { students, faculties and parents with general publics. A total of } 874 \text { responses gathered from people of different } \\
\text { background participated in the survey. The analysis of collected responses confirm that the traditional chalk and } \\
\text { talk methodology is often better than online sessions. Results and analysis indicated that lack of facilities, } \\
\text { infrastructure, technical tools and the internet access are the major drawback for conducting online sessions. The } \\
\text { suggestions and recommendations are provided to improve the current online teaching methods to outreach } \\
\text { many students and improve quality teaching/learning experience. The precautions to be taken by the universities } \\
\text { to avoid rapid spread of CovID-19 cases are high lightened, if colleges/universities opens before vaccination. }\end{array}$ \\
\hline
\end{tabular}

Keywords: COVID-19, lock down, Higher education, online learnings, traditional teaching

\section{INTRODUCTION}

In Wuhan, the pneumonia of unknown cause was first detected and reported to World Health Organization (WHO) Office on December 31, 2019 (Wang et al., 2020). Since then, this epidemic spread all around the globe (Guo et al., 2020). World Health Organization broadcasted the name novel corona virus disease (COVID-19) on February 11, 2020. WHO announced the COVID-19 is a pandemic on March 11, 2020. On September 26, 2020, there were 32,110,656 active cases with a death count of 980,031 in world (Worldometer, 2020). On September 26, 2020, India reported there are of total 960,969 cases and 93,379 deaths (MoHA, 2020). Coronavirus is affecting the normal life in every possible manner. An unprecedented worldwide lockdown has not only made our life miserable, but also imposed us to live inside our homes. Extremely rare events like this are witnessed only once in a lifetime or two. Indian government announced we need to adjust to this environment, by maintaining social distance among themselves (MoHA, 2020). The lockdown effect shuts almost all sectors which made large impact on economy in most of the countries (Stefana et al., 2020). The country's economy is affected badly by the following sectors such as, automotive, transportation, shopping malls, hotels, restaurants, tourist, sports leagues (NBA, FIFA, IPL, WWE, Formulae 1, golf) and public events, airbus, service sectors (amazon, flipkart, ekart), education and so on (Fernandes, 2020). Many of the aforementioned sectors are re-opened after undergoing lockdown period of 50-70 days. However, still the educational institutions remain closed as they find it difficult to maintain social distance in place.

In India, higher education system at present is at a transition stage. A stage where changes have taken place for good and more transformations in thoughts and processes are desired. Higher education system in any nation today seeks a relook. Higher education for academic institution and students must cope up to online teaching aids still remains a big question in the emergency situation of COVID-19 (Bao, 2020). COVID-19 enforced the academic higher education universities across globe to cancel the traditional chalk and talk (in class face-to-face education) methodology and change to the online teaching/learning (Bao, 2020; Dilucca et al., 2020; Wang et al., 2020). The change originates the challenge of sensitivity of learnings and new opportunities that the technology offers. This changeover has been easy for the autonomous/deemed and private institutions, in the other hand it is a challenge for the public ones. As the COVID-19 emergency arises many universities in India to temporarily close the onsite classes. 
Further, some of the universities have decided to start the online classes to the students in a trial basis in the urban areas. This sudden transition of teaching methods to online classes made students and faculties in a confused mode. The ongoing online classes is now turned out towards the question of learning quality (Crawford et al., 2020).

Many universities started claiming that they have started the online classes and admitted that the successfully reached $90 \%$ students and created the facilities online. Some universities have openly agreed that the changeover of teaching method is difficult to communicate and access to internet. Institutions have tried many methodologies during the start of lockdown to continue the curricula through recorded classes, uploading in the social media or in the websites. Students who have proper access of internet may study, others it's a difficult task (Ary \& Brune, 2011). The other method is live classes/online classes. Reaching students through live classes institutions must have uninterrupted high-speed internet, infrastructure, a software tool to reach the students and the comfort. Online education is not just oral presentation of the faculty on the computer/laptop/mobile phone or it's not just listening at the other end by a student. Online teaching methodology poses many challenges due to inexperience in conducting/attending live classes by faculty and students and lack of early preparation or support from educational technological teams (Wang et al., 2020).

There may be many advantages and disadvantages of online classes for both faculties and students. For teachers, online classes allow new method of teaching with access of advanced tools and technology involved in it and can reach to many students (Appana, 2020). Contrary, student can acquire knowledge of using different online tools and methods, pay much attention to recorded/live conversations of world class professionals, listen and watch classes many times and working at their own promptness (Arkorful \& Abaidoo, 2015). Inability to have a face-to-face connect with students and facilitate free conversations, discussions, and mentoring, lack of online teaching experience consumes more time and practice, technological difficulties with high speed internet access and getting used to learning and being evaluated online are identified as major limitations (Arasaratnam-Smith \& Northcote, 2017; Claywell et al., 2016; Sun \& Chen, 2016).

The study on Higher education degree courses during lockdown period of the COVID Pandemic situation in India, decision has taken to conduct classes through online mode. Higher education starting from Bachelor of Arts, commerce, science and all technical education have started the online classes to their students using online tool.

The aim of the study is to investigate/identify the knowledge, practice and utilization of online courses and the quality of understanding amongst the students and faculties during lockdown period of the COVID-19 pandemic situation in India. The study also analyses the quality and outreach of the online classes with various stake holders of different higher education streams through online Questionnaire based survey. In addition, suggestions and recommendations are high-lightened to impart better teaching and learning experience viz. online mode.

\section{METHODOLOGY}

A web-based survey has been conducted through the set of questionaries' from the various higher education institutions composed of both students and faculties. The acquired knowledge and technical aspects of online teaching is often difficult to correlate with the quality of the learning experience (Kebritchi et al., 2017). A paradigm shift from traditional in-class face-to-face education to online teaching during COVID 19 has determined lack of availability of internet facilities and technical support. The Outbreak of CORONA Virus in India was officially confirmed in the month of January and the higher education institutes have already started their curriculum and the seriousness of COVID-19 was reported in the early month of March. The cluster of few cases of COVID-19, which results in closure of lower education institutions and their activities in the third week of March.

Higher education authorities in consultation with health department has instructed to close the academic activities to control the COVID 19 disease through set of measures. The Prime minister of India has taken a decision in view of CORONA disease to maintain Quarantine Lockdown to cover the whole regions of India. Ministry of Human Resource and Development (MHRD) recommended the universities of higher education to conduct online classes for uninterrupted learning.

World-wide transition change takes place in education sector to conduct classes online, which has faced several difficulties to achieve effective teaching/learning. Prior to online teaching, the faculty must be cleared regarding the effectiveness of technological software's adopted by premier institutions for online learning during this emergency COVID-19 pandemic. One should understand that this online learning/teaching is a momentary teaching aid and an alternative mode to combat the situation of COVID-19 crisis. Note that, online learning has made more disproportion problems that may cause students mental ability to learn more effectively, and be fruitful. Attentive, methodical and regular concentration will be necessary to change the mind-set to shift to the online teaching/learnings from traditional method. There are chances that many students may not be having access to the network or internet facilities. Especially, in India many rural places it's often difficult to reach out to the internet or any other technical equipment's. Time management, teaching styles, paradigm shift from traditional chalk and talk to online, content development and effective delivery through the integration of multimedia is a challenging task for faculty members. Planning to have a systematic meaningful learning's is a challenge for both the faculties and students. Communication is the key factor particularly to understand the one behaviour through online education system, irrespective of pros and cons. It's being much difficult for a faculty to address and clear the doubts of a student through effective communication. In this emergency crisis, paradigm shift of Indian traditional chalk and talk method to online teaching still remains a big challenge. To achieve a clarity and the reality answers to these areas, all stake holders starting from parents to administrator to teachers to educationalists are responsible.

The online education systems are separated each other (student and the faculty) and the education administration mandated to learn online for students and teach by faculties. It's also a challenge and the indenture amongst the faculty and the student, 


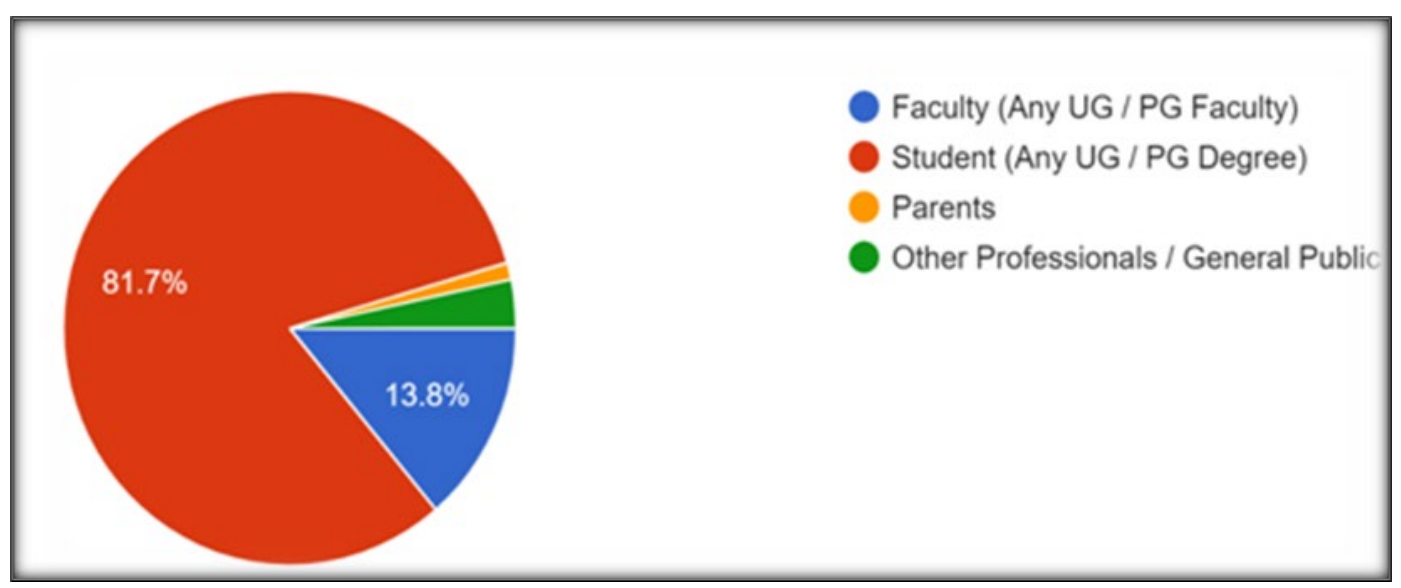

Figure 1. Various stakeholders participated in the survey

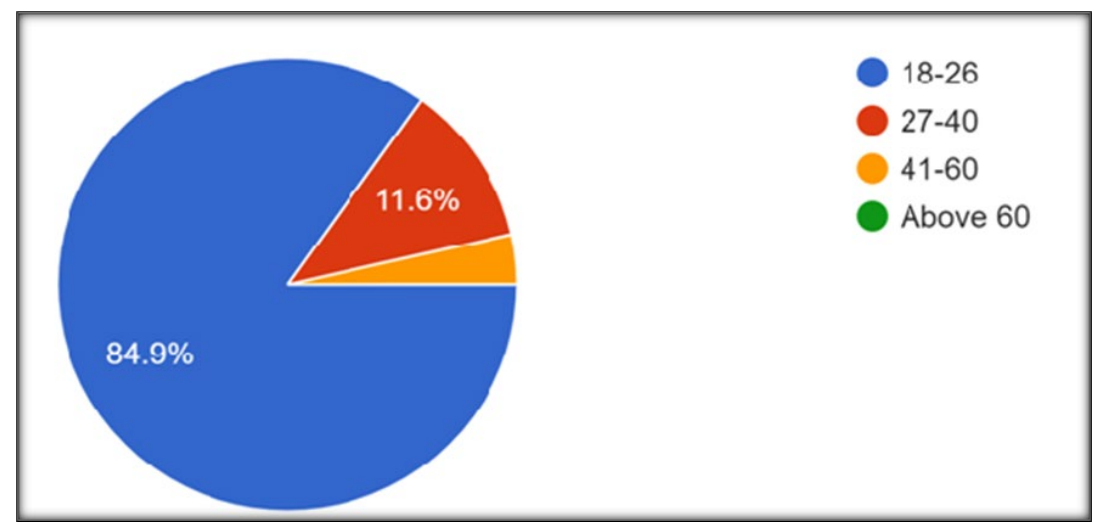

Figure 2. Age group of the stakeholders participated in the survey

entails to guide and prepare for the academic examinations. Keeping these points and the present education directions in the essential service during the corona emergency, education sector also plays a vital role and a survey indicated the overall pros and causes. The present survey is conducted by considering stakeholders of all the higher education courses.

The survey was conducted amongst the students, faculties, parents and other professionals/general Public with different age groups. The total of 874 responses were recorded, among them $81.7 \%$ are students, $13.8 \%$ are faculties and remaining are professionals/general Public as shown in.

The survey is composed of set of questionaries defined through brainstorming technique. The questionaries are framed after conducting the brainstorming sessions carried out with the academic experts (technical, science, management, medical and so on) heading the institutions/universities in a different role. The collective opinions of all experts confirm that the teacher's delivery and student's understanding capability in online classes could decides the efficacy of Teaching Learning Process. In view of above, questionaries are framed, and prepared questionaries are shared in online platforms (WhatsApp, Social Media Sites, Email) to seek the honest opinion from teachers, students and publics (who are also be the teachers of different background) by filling google forms. In this regard, responses are collected from the 874 participants through online mode of google form platform for analysis. Please note that, In the google form we have provided sufficient space, wherein the participants are allowed to express their views or suggestions and recommendations to improve the quality in Teaching Learning process.

Figure 1 shows that $81.7 \%$ students from various courses have participated in the survey. This is obvious that students are the most affected in this emergency crisis. The survey forms are spread among the student community irrespective of the degree courses they study. The faculty members composed of different streams responded about their experience of online teaching (content delivery, student response, technology used, software available and so on) and showed their eagerness to know the consolidated summary of the conducted survey. In addition, the survey also incorporated the age group as prominent questioner to know who most interested participants are. It is evident that $84.9 \%$ respondent fall between the age group of 18-26 years (most of them are identified as students) and $11.6 \%$ from $27-40$ years (faculty members) and the rest were above 41 years (professors, parents and other professionals) old.

The questionnaires and the survey were opened to fill from all higher educational degrees. The survey form filled from different streams are technical (Engineering/Diploma disciplines), basic degree (science/arts/commerce) courses, management, medicine (medical, dental, ayush), law/journalism course degrees, library science, sports, horticulture, forestry, dairy, home sciences degrees and so on. It is important to note that, responses were collected from different states (Karnataka, Tamilnadu, Andhrapradesh, and Kerala) of India. Many Premier Institutions/universities with QS World ranking less than 500, were located in these regions and they also participated in the survey. Out of 874 responses, $85 \%$ respondents are from 
Table 1. Details of age group of the stakeholders for Figure 2

\begin{tabular}{ccc}
\hline Age Group & Number of responses \\
\hline $18-26$ & 742 \\
\hline $27-40$ & 101 \\
\hline $41-60$ & 28 \\
\hline Above 60 & 03 \\
\hline
\end{tabular}

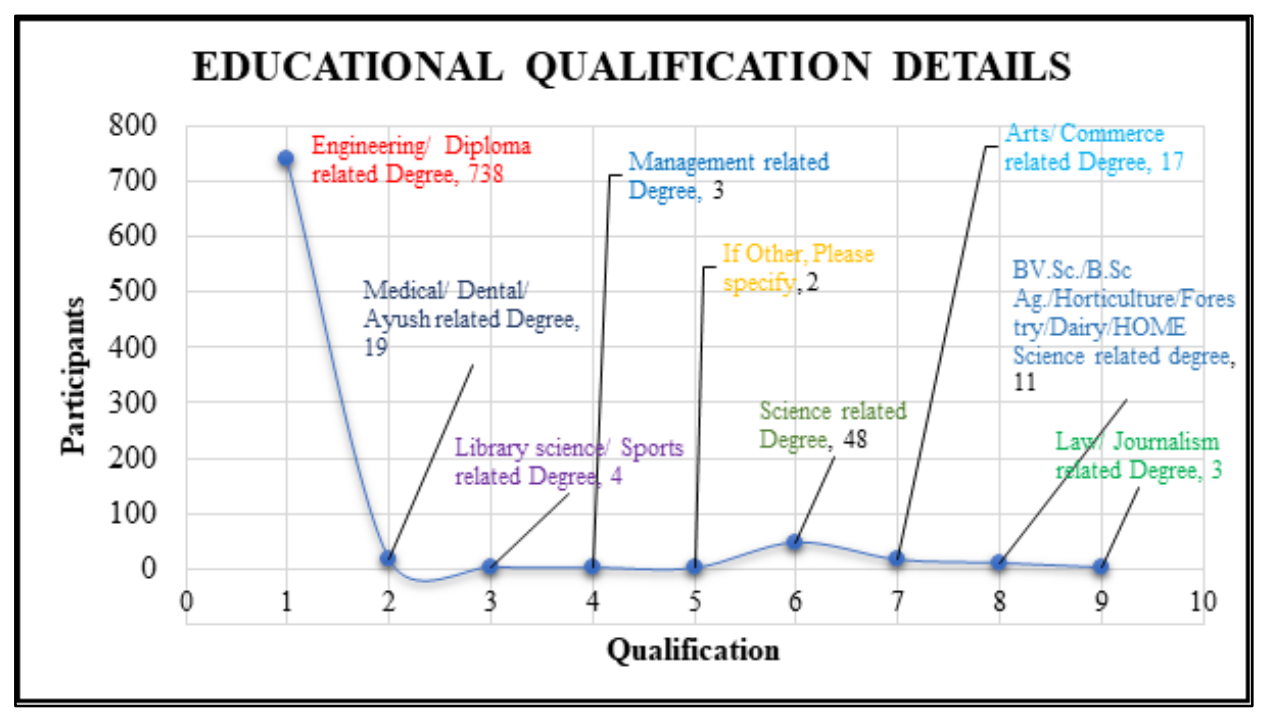

Figure 3. Educational qualification details of stake holders

engineering/diploma/technical Courses and 5.9\% from basic science courses, $2.2 \%$ from medicine related courses, $2 \%$ responded from arts/commerce related courses and rest with other degree courses as discussed above as shown in Figure 3.

In many developing countries including India the land area is divided into many provinces. To have control over administration, the provinces are sub-divided to rural, urban, taluk headquarters, district headquarters, metropolitan city etc., based on the area and population. The facilities, in particular high-speed internet access required for online teaching vary from place to another. In the survey form, a questioner has been framed to understand the efficacy of online teaching for various people due to COVID-19 lockdown at their native place. The respondents were locked down at these various areas and it is observed that $49.3 \%$ are from rural, $31.7 \%$ are of urban, $7.8 \%$ are from district headquarters, $6.6 \%$ are from taluk head-quarters and around $4.6 \%$ are from metropolitan city as referred in Figure 4. The geographic location of the respondent is of paramount importance to study the accessibility and comfort of technical issues such as internet networks, content delivery methods by faculty members to outreach every student, possible fruitful discussions as and when the doubts raises are the major issues in the online learnings. These new techniques and online studies empower the student to learn whenever and wherever they can. In addition, the sessions can be viewed multiple times if stored in online platform and understand. It is clear that majority of the respondents are students from rural areas, facing badly with fast internet access, power problems followed by limited internet data (maximum of 2 GB data per day is not sufficient to attend 3 hours continuous lectures) attend online classes conducted by the faculties. This clearly indicates the technical difficulties faced by students to ensure quality learning experience at rural areas. Although other areas do not have power problems, but insufficient internet data package and low speed internet access possess technical difficulties. In addition, understanding the mathematical and analytical subjects through online teaching often identified as major drawbacks. The rural background people also find it difficult to have accessibility to high-cost learning aids (i.e., computers/laptops, smartphones) which are the essential requirements of online learning.

India accounts for $30 \%$ of the world's total illiterate population and around $70 \%$ of these illiterates are women. As per 2001 Census data, women constitute $48 \%$ of the total population in India, but around $46 \%$ of women are still found to be illiterate. Problems of gender disparity and discrimination begin with access to schooling to higher education. While gender inequalities intensify with poverty, caste inequalities and geographical location (particularly in underdeveloped rural areas), particular gender-differentiated ideologies cut across all social groups, explaining why in all social groups, girls lag behind boys in access to and participation in education. In the present survey, to overcome with these gender-discrimination, it is been included along with transgender too in the other category. Among the respondents there was 634 male participants, and 240 female participants were involved in the survey that accounts to $72.5 \%$ of Male and $27.5 \%$ were female participants (refer Figure 5 ). The number includes all the participants from various streams (Basic Science, Engineering, Medical, Agriculture etc.,) with different demographic locations and age groups (refer Figure 4 and Table 1 ). 


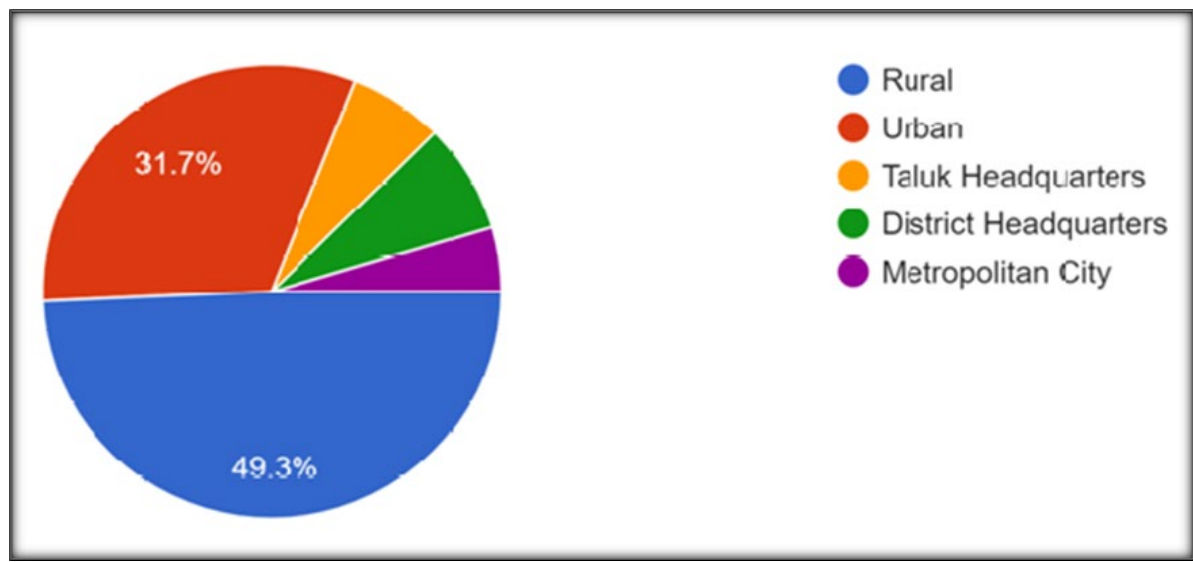

Figure 4. Demography of the stakeholders participated in the survey

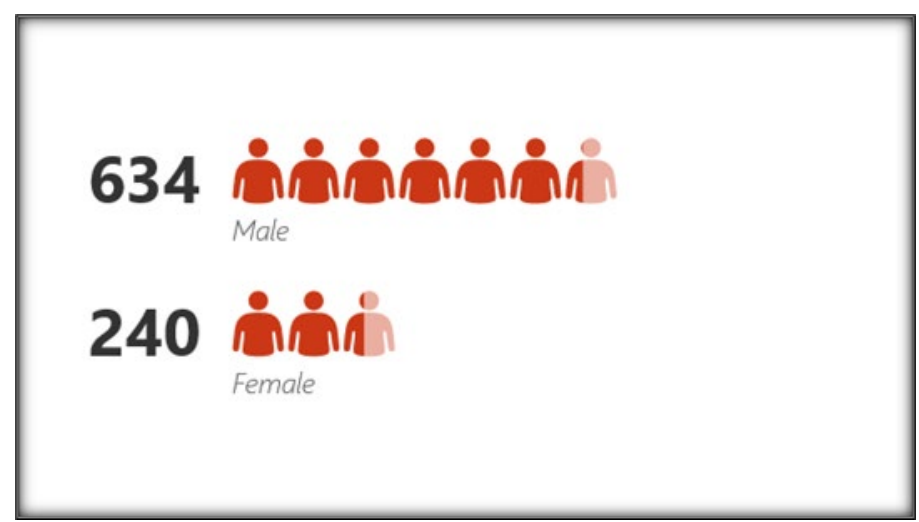

Figure 5. Sex of the stakeholders participated in the survey

The questionaries are framed from the collective suggestion and recommendation by experts after conducting brainstorming sessions in view of online education system during the lockdown period. Questions are framed to know the common and essential requirements that could help to understand the efficacy of current online teaching-learning in comparison with traditional in-class face-to-face teaching process. The survey has been carried out through Google forms online platform shared viz. social media (WhatsApp, Facebook, Instagram) and email. The Google form consists of the following questionnaire,

1. Which mode of the learning/teaching you prefer?

2. Your opinion on Online Teaching?

3. Which online tools you are aware of?

4. Do you feel online class creates curiosity?

5. Which type of course was more effective to understand through online?

6. Convenient time for online teaching/learning?

7. Do you feel revision of the topics require after college re-opens?

8. Do you feel that COVID - 19 lock-down affected the placement activities?

9. Do you feel lock-down affected your individual/professional growth?

10. Do you feel laboratory/practical teaching through online mode is effective?

The questions are framed with two or more specific options to select the answer for the respondent. For each question, sufficient space has been provided to suggest or recommend his individual opinion.

\section{RESULTS AND DISCUSSION}

The survey findings gave the insight of stakeholders' perception and the methodology of course/content delivery. The survey also analyses the facts and efficacy of quality teaching/learning, interaction/communications amongst the students and faculties. This survey developed to maintain consistency towards the design of curriculum for online learnings, required technical facilities compared to traditional chalk and talk. Results and responses of the questionnaires framed is discussed in this section.

\section{Teaching Methodology}

The opinion of various stakeholders (students/faculties/parents/academicians/other professionals/general public) were collected to know their like lines in traditional in-class face-to-face teaching or online teaching. Interestingly students have 


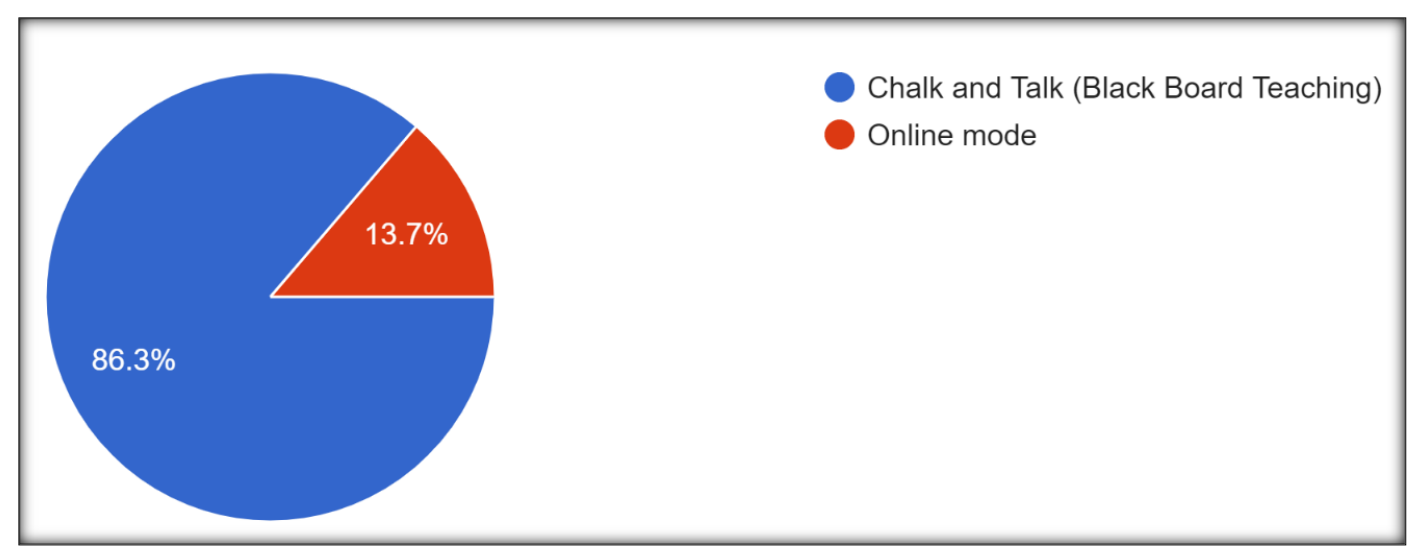

Figure 6. Stake holders' response for mode of students

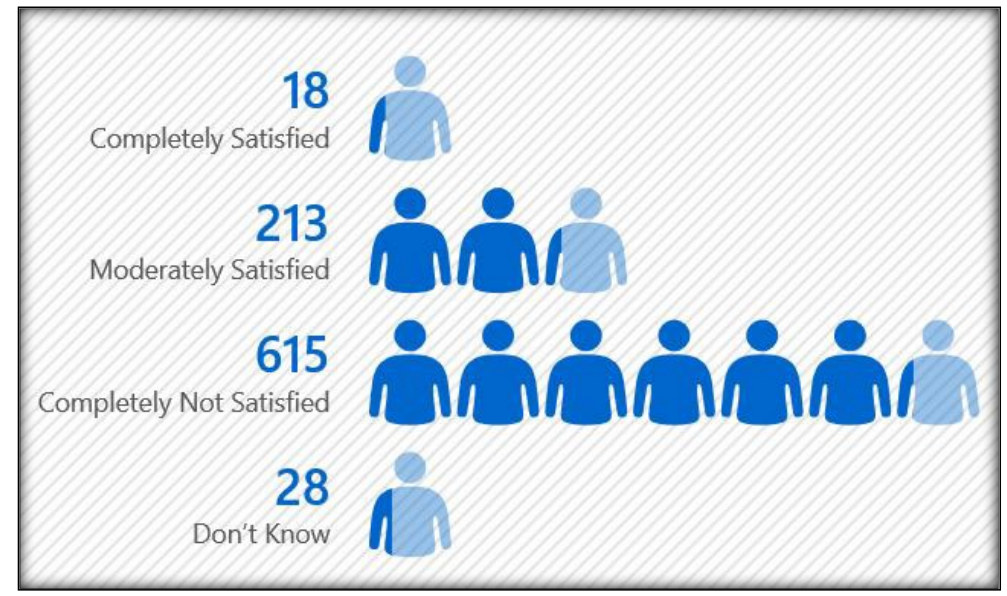

Figure 7. Participants satisfaction on online class

responded to have traditional method of teaching is better than online teaching. As shown in Figure 6, out of 874 responses, 754 members (86.3\% participants) have responded with their preference given to traditional in-class face-to-face learnings. Irrespective of different courses and degree background all stakeholders feel that the traditional teaching creates more interest and can clear doubts through interactions. In traditional method one to one contact and face to face communication will happen. Although, current generation students are more adopted to advanced technologies, but still, they are keen to learn through traditional method. This might be due to lack of high-speed internet access, limited network data per day, power supply and technological gadgets (laptops, android sets, micro-phones and so on). However, 120 members (13.7\% of participants) recommended for online teaching and approximately $90 \%$ among them are from urban areas. (Taluk, district and metropolitan city). This may be predicted that the urban based participants have sufficient technical tools and facilities.

\section{Satisfaction of Online Teaching}

Opinion is asked to all the participants to give their consent regarding online teaching satisfaction. In online teaching and learning, all the student and faculty participation are equally important. The satisfactory levels (completely satisfied, moderately satisfied and completely not satisfied at all) regarding online teaching is the answer for the question framed. The analysis of 874 respondents showed approximately $70 \%$ participants given their consent towards completely not satisfied. Around $25 \%$ of the 874 respondents have agreed they are moderately satisfied. The quoted reasons for dissatisfaction with online teaching/learning might be due to lack of technical facilities, power problems in rural areas and so on. Few of them suggested that lack of technical knowledge in usage of online session tools to deliver the contents efficiently. Very few have agreed that they have fully satisfied as shown in Figure 7. "I am not an enthusiast of online teaching. We need a human interface with students for good communication. That is how young minds can be inspired" The statement made by Prof. CNR Rao on the online teaching. Online teaching effectiveness towards the improvement of the student community may not be satisfactory and new strategies to be incorporated to overcome the same.

Some of the comments reported towards the satisfaction of online courses are as follows, a) online classes affects the student's ability to listen and interact. b) The faculty will not be able to judge student's reaction such as the student's attention and voice will be muted. c) Interaction is the key to success in teaching. d) Instead of conducting online classes at the specified time, students suggested to upload recorded class videos such that the students can relook over a period of time and seek questions during the next online sessions. e) Technical and infrastructural problems are other issues, wherein the screen shared by faculties during online sessions is not clearly visible on smart phones. f) Mathematical and analytical subject content delivery is often found 


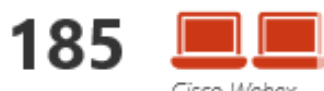

Cisco Webex

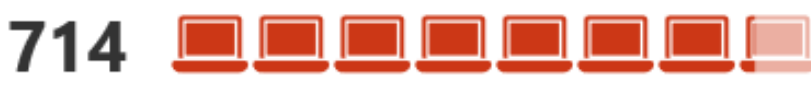

Zoom

$72 \underbrace{\square}_{\text {GotoMeeting }}$

$247 \underset{\square}{\square} \square$

$7 \underset{\text { importus }}{\square}$

Figure 8. Tools for Online Courses

difficult to understand and interpret during online classes. g) one participant commented that, online teaching can effectively replace classroom teaching only for those of interested faculty and students.

\section{Online Teaching Tools}

Majority of the online classes are based on the internet/network web based. Education technology has opened new avenues, enabling everyone to monetize their skills. As the world is living with digital technology, various online teaching aids are available and are very useful. The students and faculties must learn how to use online teaching aid tools effectively and quickly, many webbased software and apps are developed for this purpose. In the COVID-19 emergency situations, to teach online these digital resources make learning more conveniently and interactive with improved versions of tools.

Online teaching tools offers significant benefits such as recording the classes/sessions, sharing voice/text messages, software's are available for both recording and editing audios, a tool for creating online spoken assignments (using images and videos), providing feedback to students, and so on. However, trial run version software's are limited to five voice threads such as the file once created cannot be deleted, zooming and other multi-rich presentations for content delivery options are not available, platform for creating websites, blogs and e-portfolios using drag-and-drop method.

A question was framed to know the knowledge of the participants on which tool the online teaching and learning is carried out. Majority of the participants have responded that they are using the Zoom software application to teaching and learning online. $81.7 \%$ of participants were agreed to have best utilization of zoom application and rest of the participants were using other online teaching tools which is shown in Figure 8.

From this question it is revealed that most of the institutions were aware of many teaching-and-learning tools. Some of them have expressed that which tool is more effective. Many universities/institutions have procured the software teaching tool as academic licence and setup their own studios to teach online with no interruption. Setup of own studios for teaching online consumes more data memory and faces buffering problem due to low-speed internet access. Each student has been given a login and password, he must login as per the prescribed timetable with teaching tool.

\section{Curiosity of Online Courses}

"The important thing is not to stop questioning. Curiosity has its own reason for existing."- Albert Einstein. As the saying indicative to this situation of online teaching and learnings, curiosity plays a vital role amongst the students and faculties. Curiosity makes subsequent learning and rewarding. Its occasional chances to the faculties to make online classes for the student to expedite curiosity, motivate and make them to involve in learning. Everyone experiences different levels of curiosity, depending on their personality, previous experience, background, and a wide range of other factors. In this section, students and faculties were asked about the curiosity of online courses.

$72 \%$ of the respondents are not curious in online teaching during the lockdown of COVID-19 pandemic. The results comprising the opinion of both students and faculties. $19.2 \%$ of respondents showed they have moderate curiosity. With different degree courses the same opinion as recorded and it is proven that the organization of class and methodology adopted may be a reason to answer this question. The results illustrate in Figure 9. 


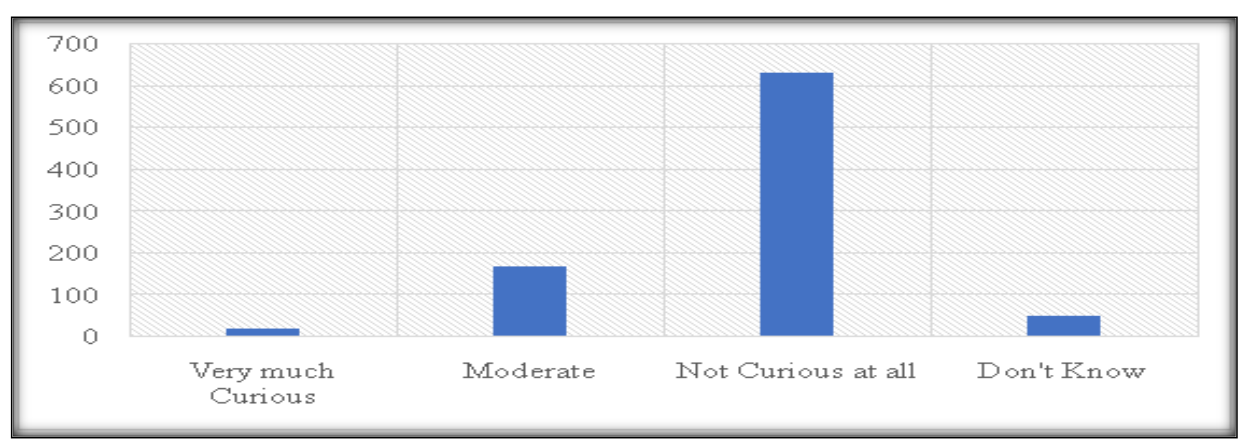

Figure 9. Curiosity of Online Courses

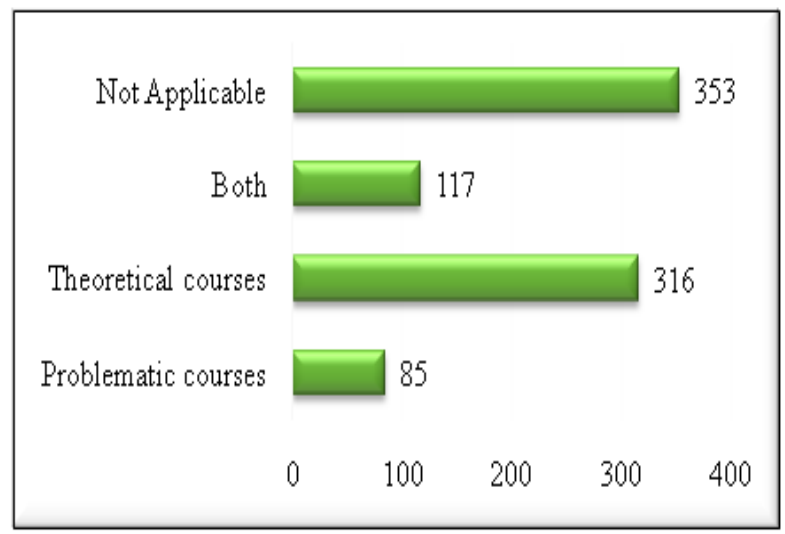

(a) Responses of all stakeholders for various courses

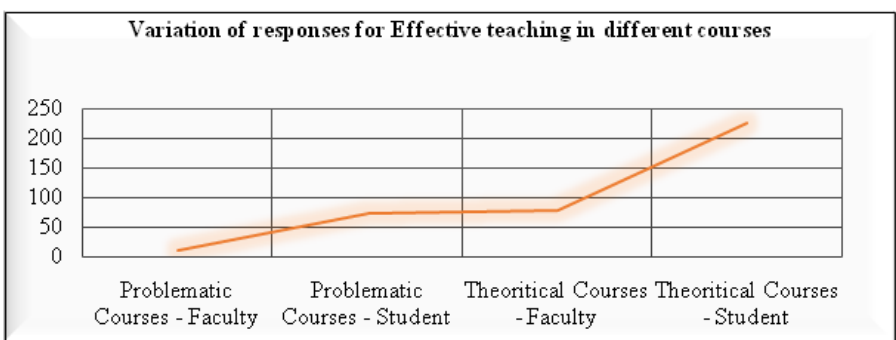

(b) Responses of Faculties and students for effective teaching of different courses

Figure 10. Responses on which type of course was more effective

\section{Effective Type of Course}

In higher studies, one course is composed of different subjects like theoretical, analytical, technical, numerical, management, drawing oriented and practical/laboratory. In view of above the participants were asked which type of courses was more effective to understand through online. During online classes it seems more often that many faculties facing problems in teaching some special subjects which they need face to face interaction. This question was answered by most of the students and faculties. This has been expressed by the students in the comment during the survey. For instance, few students expressed their experience in the comment section like, for practical and problematic subjects, online teaching is often quite difficult to understand for the students. Some have expressed like, "Problematic subject very difficult to understand".

Effective learning can only be accomplished with mutual interaction among the student and faculty, wherein the communication is a major drawback unless trained usage of online tools, infrastructure and other technical tools essential for content delivery in online teaching. This shows direct reflect on online teaching and learning for different subjects are shown in Figures $10 \mathrm{a}$ and $\mathbf{1 0 b}$. The options given to respondents to answer this question are i) problematic subjects, ii) theoretical subjects, iii) both type of subjects and the last option is iv) not applicable as the participants are from different sections like engineering, medical, Pharmacy, Law, Agriculture etc., A total of 316 responses are received in favor of theoretical based subjects are more effective in online classes. Very few responded as problematic subjects are effective in learning in online mode. Interesting to note that, 117 participants have given their opinion of both theoretical and problematic subjects are effective through online classes. This question cannot be holds good for all the courses, most of the courses (excluding arts and law) have practical oriented/project oriented and the answers needed in the exams are descriptive method. 


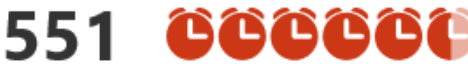

Morning 8-72

\section{5 ć心゙́ি}

Afternoon 12-4

88 누

Evening 4-8

Figure 11. Suitable time for online teaching responses by the stakeholders

\section{Convenient Time for Online Teaching}

During the COVID -19 lockdown period all the students and faculties are considered to be free. Many universities have given freedom for their faculties to do academic activities (teaching/learning, research, conduct webinars/workshops and so on) with work from home concept. In addition, flexibility has also given to conduct online classes according to their convenient time. Some institutions prepared timetable for each subject to conduct online classes. The biggest problem involved in this pandemic situation is, students stayed at hostel premises, paying guest rooms, relatives houses near to college campus are moved back to their native places (many are from rural background) facing network access and other infrastructure and technical problems for attending online classes. In addition, power problems, network data access and lack of technical infrastructure are other major drawbacks to attend classes for the institute scheduled time to attend online classes. In this regard, an opinion seeking from all the participants during this survey that, which is their convenient time for online teaching. The participants are asked to select the preferable time for online classes, a) morning 8 to $12 \mathrm{AM}$, b) afternoon 12 to $4 \mathrm{PM}$, and c) evening 4 to 8 PM. $62.9 \%$ of 874 participants have responded that morning 8 to $12 \mathrm{PM}$ is the convenient time, $26.9 \%$ of 874 participants responded that it is better to have afternoon 12 to $4 \mathrm{PM}$ and $10.2 \%$ of 874 participants feel that evening 4 to $8 \mathrm{PM}$ is convenient time for online teaching/learning as shown in Figure 11.

\section{Revision of the Topics}

Revision must be one of the most individualized processes within the academic life. Students begin it, with different sets of knowledge and understandings, different responses to the stress of the revision and exam period, different revision techniques, psychological and life contexts into which to fit the revision. Many students in social media and during teaching given their consent we are not fully understood the concepts due to infrastructure, technical and power problems. In addition, online teaching has its own biggest problem wherein face to face interaction, expressions are not possible to clear the doubts raised by students within the specified time. During this emergency situation of COVID-19, paradigm shift in learning methodology, uncleared concepts, lack of facilities and finally to face exam based on online teaching may disturb mental stability of the students. In India, corona virus is spreading rapidly and higher education administration have decided to conduct examinations. In view of students the survey has taken whether you require revision to face the examination.

The importance of revision is two-fold. Firstly, it helps you to remember facts, figures, topics and methodologies that you have covered some time ago. Secondly, revision help to reduce anxiety, stress, and increase student confidence in preparing and writing examination. This will be easy for the traditional face to face teaching, whereas the online teaching in COVID situations many students regularly have not attended the classes due to various reasons.

In view of above, keeping students learning quality perspective all the participants are asked to fill the answer (either yes or no) for the question, do you feel revision of the topics require after college re-opens. Noteworthy that, $96.3 \%$ participants have responded yes, meaning they require revision with traditional in-class face-to-face teaching at classroom, once the institution/university reopens after the COVID emergency lockdown as referred in Figure 12. However, 3.7\% students have responded that they don't need revision because they are from urban background with well-established infrastructural, technical and high-speed internet access facilities to attend all the online classes. 


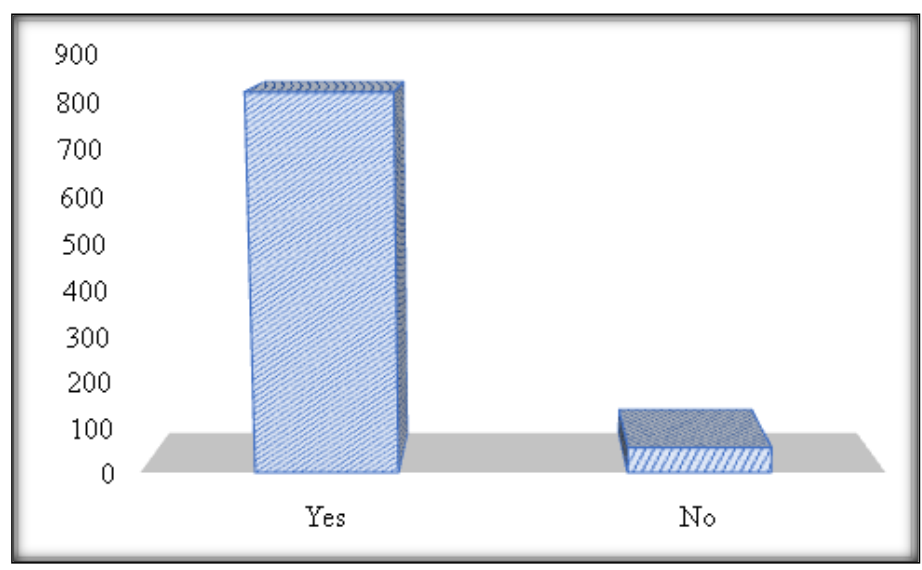

Figure 12. Stakeholders opinion on revision of topics after college reopens

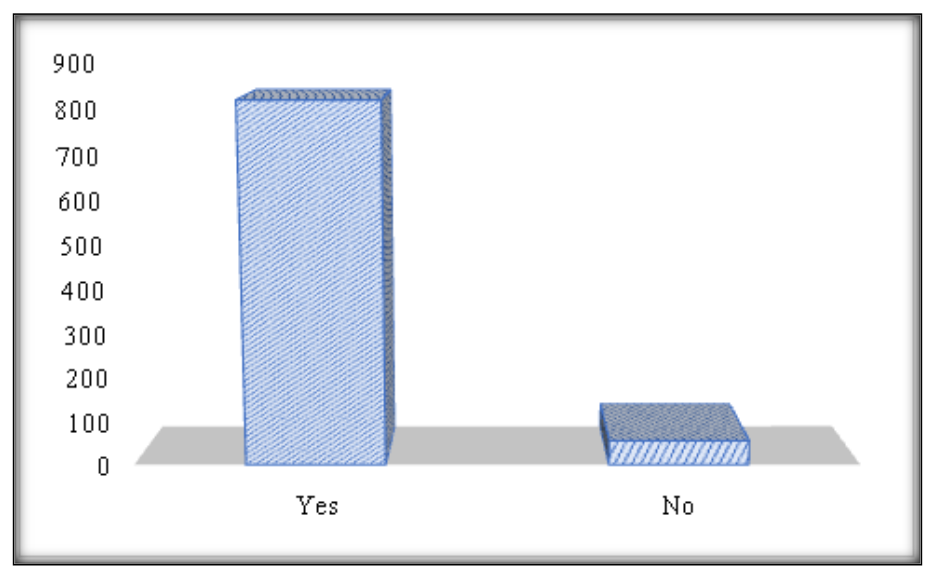

Figure 13. Responses for Placement activities are affected due to lockdown

\section{Placement Activities during COVID-19 Lock-down}

In the light of rising concerns about the COVID-19 spread, many companies have put hold on their placement process. This occurs due to economic slowdown worldwide, shut-down of companies and so on. In India, Colleges are facing a tough year ahead with disruptions in their campus recruitments as the pandemic affects the businesses worldwide. Generally, most business and engineering schools conduct campus placements between December-to-April month, every year. While many students have been placed already, some still struggle to find a good job offer. In the wake of coronavirus outbreak in the country, students who got campus placements are left in a lurch as some companies have begun delaying offers, while some have withdrawn their offers. But now, as the coronavirus has led to a shutdown of educational institutions as well as businesses, the placement process has been halted or left incomplete at different stages for different institutions. During the survey most of the students feels that placement activities have shut and no placements, especially for the final year students. In view of above, "Do you feel that COVID - 19 lock-down affected placement activities?", question was framed to know the opinion about the placement drives. Note that, $92 \%$ of the participants feel that there are no placement activities on-going and it definitely reflect their career due to the COVID19 pandemic as in Figure 13.

\section{Individual Growth}

A question, "Do you feel lock-down affected your individual growth?" is framed in the survey to know the status of individual growth. Note that, $72.4 \%$ participants feel that it affected the individual growth and $22.4 \%$ feel unaffected as shown in refer Figure 14. Worrying about when this will all come to an end and start thinking about ways to get through this period better and unaffected as much as possible. One of the most affected sectors due to the COVID-19 pandemic is the education sector with millions of students worldwide losing valuable school time and missing out on lessons. But there are numerous ways to access their lessons online. While some see this as a painful period to get through as quickly as possible, others consider this a great opportunity for self-development and personal growth. We have to realize that this is probably the most amount of time we could get to spend by ourselves in our lifetime. Making the most of it like a true opportunist would certainly help us in the long run in tremendous ways. 


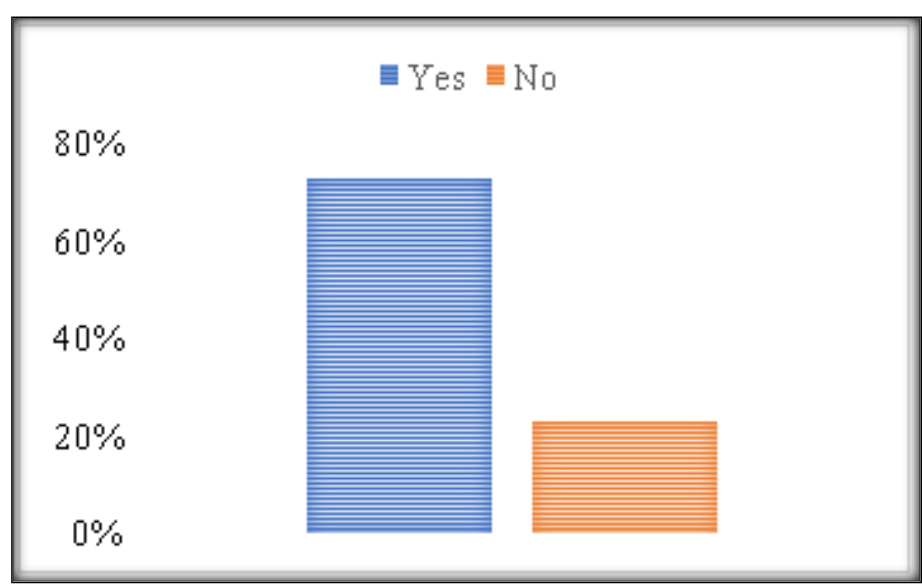

Figure 14. Responses for individual growth affected because of lockdown

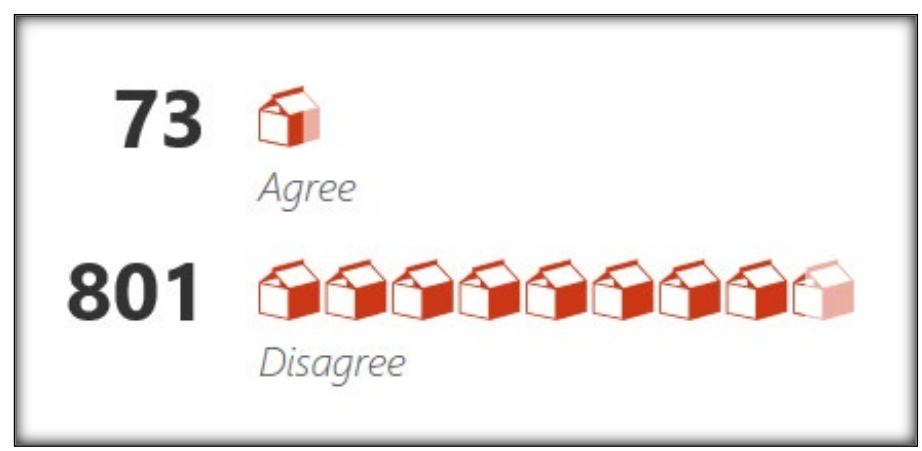

Figure 15. Responses for Effectiveness of labs teaching in online

\section{Laboratory / Practical Teaching through Online}

The query has been framed to know the efficacy of laboratory and practical method of teaching online. Interesting to note that 800 participants given their consent that they are completely disagree in learning practical's viz. online mode. However, 74 respondents feel they agree online sessions for practical/laboratory learning as shown in Figure 15. There is a general agreement in the engineering/medical/agriculture/sports education courses, wherein laboratory work is a vital adjunct to lectures and other work in achieving degree know-how. Practical's/laboratories is an applied science that requires considerable hands-on-skills and laboratories can be helpful in providing this. There is no doubt, that many degree courses in higher education has become more theoretically based over the past 50 years and the learning emphasis has unfortunately moved towards lectures and classroombased education to practical and lab or project-based hands-on learning. In the emergency COVID-19 lock down of all the institutions were closed and started online classes. Though, theory classes can be taught through online. But, for practical/laboratory classes it's very difficult to know the complete insight of process for both students and faculties. The difficulty can be overcome by conducting laboratory/practical teaching via online platforms preferably using Virtual lab setup developed by various Indian Institute of Technology (IIT's) for Engineering courses. Also, by conducting the live lab sessions / recorded videos.

\section{Re-opening Schools and Colleges before Vaccination and their Precautionary Measures}

Reopening of schools and colleges before vaccination may definitely increases the number of COVID-19 cases. Therefore, India is planning to lift progressively the rigid social restrictions implemented with lock down and offered different options for universities/institutions to be chosen regarding reopening of schools. The precautions to be taken by the universities to avoid rapid spread of COVID-19 cases are listed below,

1. In addition to social distance, re-opening of schools requires large-scale trace and testing to isolate the asymptomatic, symptomatic and COVID-19 positive cases.

2. The management authorities of universities have to think of re-opening in stages,

Progressive re-opening: Approximately $25 \%$ of the students are allowed to go for college/universities for physical classes in the $1^{\text {st }}$ week after lock down lifted, followed by gradual increase over the weeks, i.e., $50 \%$ in the $2^{\text {nd }}$ week, $75 \%$ in $3^{\text {rd }}$ and $100 \%$ in the $4^{\text {th }}$ week.

Partial re-opening: $50 \%$ of students are allowed to attend physical classes in $1^{\text {st }}$ half of the week (Monday to Wednesday), and remaining $50 \%$ students in the next half of the same week (Thursday to Saturday).

3. Health screening tests (i.e., temperature or symptom check before entering the campus) are to be conducted for students and staff of colleges/universities every day. 
4. If students or staff found any symptoms of suspected virus or if they been in contact with the one who is infected with virus are immediately sent home for isolation, or undergo home quarantine with medical treatment for a period of 14 days. If any individual found symptoms are to be taken to hospital for examination and ensures they have completely recovered before return to school. Note that, for health perspective of any individual the classes are to be suspended for a period of 14 days, if any positive case is reported. If more than 3-5 positive COVID 19 cases reported in the class, then better to shut down the schools and colleges for a period of 10-14 days.

5. To maintain social distance inside the class room, the class size should not be exceeded more than 30. Proper monitoring must also be done with at least 3 feet distance maintaining among the individuals.

6. Management must also ensure that multiple entrances to be provided for all the classes, such that physical distancing can be maintained.

7. During mealtimes, ensure no individual must share their food and maintain physical distance. It is better to use dividers wherever possible.

8. Sports and physical exercise activities are to be suspended. If allowed for such activities that must be limited to a small group.

9. During transportation, one student in a row is allowed to sit and must be cleaned at least every 8 hours. For health perspective students are encouraged to bring their own vehicles till the COVID-19 disappears.

10. To bring awareness about hygiene, posters and videos related to hand washing, and significance of wearing face masks are to be displayed at notice boards and in public places. Further, the windows and air vents must be kept open at all times.

11. Use of wipes, frequent hand washing at least once in every 2 hours, and hand sanitizers are being the safety measures to limit the spread of COVID-19 cases.

12. Every day, it is recommended to clean the surfaces of door frames, knobs, floors, tables, desks, and other essential areas.

13. Never encourage sharing of the any materials like, books, computers, tablets, calculators, and so on. Shared materials (library books, computers, calculators and so on) must be cleaned/sanitized before being used by other set of students.

14. It is essential to ensure transparent dividers must be placed on the desk to ensure separation among the individuals.

\section{Digitally Connect to Students for Conducting Effective Online Classes}

The major role of government during this pandemic situation is to provide the right hardware and software, high speed internet access, storage capacity, uninterrupted power supply and so on for attaining effectiveness in Teaching Learning Process. Free access for digital libraries, e-books, patents and journals to be given for students and faculties. The list of popular digital libraries in India are, Archives of Indian Labour, National digital library of India, Digital library of IIM Kozhikode, ETD at IISC, Nalanda digital library, Librarians digital library, Vidyanidhi: Digital library and E-scholarship portal, Indira Gandhi national centre for Arts digital library and so on. For an effective online learning experience, the designed content material must enable student to engage digitally and dynamic always. Faculties need to send the content material to the students well-in advance before starting the online class and this enable fruitful discussion after class session finished by the faculty. To enable student's attentiveness in each class, surprize quizzes and questionaries are to be mandated.

\section{Key Strategies to be Adopted for Enhancing Online Teaching/Learning Experience}

Online education has not been included in the curriculum by many institutions. Several institutions are now persuaded that online education has continued to stay, which will be part of future academic activities. Digital technologies to be included for learning management systems, enrolment and academic programs, faculty governance, assessment of students, etc. The roles of Teacher, student and Parents are equally important for adopting this, both should change their mind set toward adopting the same. The pandemic epidemic has definitely confirmed that reform is imminent, and a great combination of conventional teaching with online mode should be available. The secret to success in the online teaching learning process is that the system has to be accessible for both students and staff.

- Sudden switching for online education mode may not be able to host large scale of new users. The platform may often shutdown because of overload. Thus, gradual upload of classroom teaching videos in the online platform can be adopted such that the sessions can be viewed multiple times, as and when they are accessible.

- Internet connectivity in rural areas should be addressed as the signal connectivity of various telecoms is the major issue. Government should take measures for developing infrastructural modifications like Open Wi-Fi areas with high speed internet access with at least 4GB data pack per day, should be made available in public places and villages. Government must provide un-interrupted power supply to facilitate ease of online teaching.

- Delivery content for the teachers should be trained prior to initiate online teaching, which gives the clarity in communication and also helps to impart innovative techniques.

- Teaching content should be framed such that the length of the video should not cross 30 minutes. This will not cause fatigue on the students who are seeing the uploaded videos to online platforms such as YouTube channel.

- Government must ensure sufficient data network package (i.e., Internet data) with high speed internet access to conduct online sessions for minimum of 4 hours per day.

- Interactive animations, presentations, games should be included in the learning module to avoid the boredom of continuous talking. 
- The course materials should be made available to students before conducting online session. Students should be advised to read those contents prior to attending the online session. In online session, faculty should hold a discussion session on the topic of uploaded/delivered course materials, thus maintaining interactive sessions.

- University / Institutions should support the developmental activities related to online teaching and learning for both Faculties and students. Inside University / Institution campus, there should be online workshops, trainings, conferences to be scheduled in frequent manner and also these should be included in calendar of events.

- The universities / institutions may implement suitable strategies to encourage the completion of Projects / Dissertations by the UG / PG students. Universities has to recommend for assigning review-based / secondary data-based projects or software-driven projects to these students, rather than traditional laboratory-based studies or field / survey-based assignments, provided the prevailing circumstances.

- The teachers will be properly prepared and trained to use ICT and electronic teaching resources to address these obstacles in the future. This helps in completing some percent of the syllabus through online teaching and remaining syllabus through classroom teaching.

\section{CONCLUSION}

India's higher education system is the world's third largest in terms of students, next to China and the United States. India's Higher Education sector has witnessed a tremendous increase in the number of Universities/University level Institutions \& Colleges since independence. The COVID-19 pandemic has severely affected the economic and educational health of India. The first decision, the Central government took in the field of education was to close schools and colleges, including higher education universities. The government and higher educational institutions quickly announced that online classes will be conducted by the institutions. Paradigm shift from traditional face to face teaching method to Online teaching poses technical difficulties that affects the efficacy of Teaching-Learning Process. The survey has been conducted with various stake holders of all higher education courses to know the efficacy of Teaching-Learning process. More than $60 \%$ of the students are not ready (due to lack of technical, infrastructural, and high-speed internet access, and power supply, limited network data per day) for the online classes. Survey indicated that the online sessions of problematic subjects are difficult, but theoretical subjects are easy to understand. Most of the students felt that Morning 8-12 time is effective for conducting the online teaching. Students felt selected portions which are covered during the emergency lockdown period via online, needs to be revised in face-to-face classes after reopening of institutions. The suggestions and recommendations are made to improve the efficacy of online teaching learning process. Further, the precautions to be taken by the universities to avoid rapid spread of COVID-19 cases are high lightened, if colleges/universities open before vaccinating the individuals (public, staff and students).

\section{REFERENCES}

Appana, S. (2008). A review of benefits and limitations of online learning in the context of the student, the instructor and the tenured faculty. International Journal on E-learning, 7(1), 5-22. Waynesville, NC USA: Association for the Advancement of Computing in Education (AACE). Retrieved on 5 October 2020 from https://www.learntechlib.org/p/22909

Arasaratnam-Smith, L. A., \& Northcote, M. (2017). Community in Online Higher Education: Challenges and Opportunities. Electronic Journal of e-Learning, 15(2), 188-198. Retrieved from https://files.eric.ed.gov/fulltext/EJ1141773.pdf

Arkorful, V., \& Abaidoo, N. (2015). The role of e-learning, advantages and disadvantages of its adoption in higher education. International Journal of Instructional Technology and Distance Learning, 12(1), 29-42. Retrieved from http://www.itdl.org/Journal/Jan_15/Jan15.pdf

Ary, E. J., \& Brune, C. W. (2011). A comparison of student learning outcomes in traditional and online personal finance courses. MERLOT Journal of Online Learning and Teaching, 7(4), 465-474. Retrieved from https://jolt.merlot.org/vol7no4/brune_1211.htm

Bao, W. (2020). COVID-19 and online teaching in higher education: A case study of Peking University. Human Behavior and Emerging Technologies, 2(2), 113-115. https://doi.org/10.1002/hbe2.191

Claywell, L., Wallace, C., Price, J., Reneau, M., \& Carlson, K. (2016). Influence of nursing faculty discussion presence on student learning and satisfaction in online courses. Nurse educator, 41(4), 175-179. https://doi.org/10.1097/NNE.0000000000000252

Crawford, J., Butler-Henderson, K., Rudolph, J., \& Glowatz, M. (2020). COVID-19: 20 Countries' Higher Education Intra-Period Digital Pedagogy Responses. Journal of Applied Teaching and Learning (JALT), 3(1), 1-20. https://doi.org/10.37074/jalt.2020.3.1.7

Dilucca, M., \& Souli, D. (2020). Knowledge, attitude and practice of secondary school students toward COVID-19 epidemic in Italy: a cross selectional study. bioRxiv. https://doi.org/10.1101/2020.05.08.084236

Fernandes, N. (2020). Economic efects of coronavirus outbreak (COVID-19) on the world economy. Preprint at SSRN https://doi.org/10.2139/ssrn.3557504

Guo, Y. R., Cao, Q. D., Hong, Z. S., Tan, Y. Y., Chen, S. D., Jin, H. J., ... Yan, Y. (2020). The origin, transmission and clinical therapies on coronavirus disease 2019 (COVID-19) outbreak-an update on the status. Military Medical Research, 7(1), 1-10. https://doi.org/10.1186/s40779-020-00240-0 
Kebritchi, M., Lipschuetz, A., \& Santiague, L. (2017). Issues and challenges for teaching successful online courses in higher education: A literature review. Journal of Educational Technology Systems, 46(1), 4-29. https://doi.org/10.1177/0047239516661713

MoHA. (2020). Retrieved on 26 September 2020 from https://www.mohfw.gov.in

Stefana, A., Youngstrom, E. A., Hopwood, C. J., \& Dakanalis, A. (2020). The COVID-19 pandemic brings a second wave of social isolation and disrupted services. European Archives of Psychiatry and Clinical Neuroscience, 270, 785-786. https://doi.org/10.1007/s00406-020-01137-8

Sun, A., \& Chen, X. (2016). Online education and its effective practice: A research review. Journal of Information Technology Education, 15, 157-190. Retrieved from https://doi.org/10.28945/3502

Wang, C., Cheng, Z., Yue, X. G., \& McAleer, M. (2020). Risk management of COVID-19 by universities in China. Journal of Risk and Financial Management, 13(2), 36. https://doi.org/10.3390/jrfm13020036

Wang, C., Horby, P. W., Hayden, F. G., \& Gao, G. F. (2020). A novel coronavirus outbreak of global health concern. The Lancet, 395(10223), 470-473. https://doi.org/10.1016/S0140-6736(20)30185-9

Worldometer. (2020). Retrieved on 26 September 2020 from https://www.worldometers.info/coronavirus/ 